Проведение помесячного анализа изменения параметра $N$ при разных полусуточных границах на используемом объеме данных приводит к значительному ослаблению надежности результатов вследствие усиления влияния циркуляционного фактора на внутрисуточное распределение осадков. Тем не менее предварительный анализ помесячного хода параметра $N$ для п. Б.Елань показал, что полученный на рис.1 вид кривых формируется в основном за счет июнь-июльских значений $N$, а май и август могут существенно отличаться от средних месяцев периода невозможностью четкого выделения одного максимума в ходе параметра $N$. Для проведения надежного помесячного анализа необходимо использовать больший объем данных.
Таким образом, проведенное исследование позволяет выделить одинаковый полусуточный период («день» - $10-22$ ч м.д.в.) с максимальным вкладом дневной термической конвекции в осадкообразование в двух соседних областях Поволжья, а также оценить величину этого вклада. Термическая конвекция летом приводит к увеличению общей суточной суммы осадков в среднем не менее чем на треть.

\section{Библиографический список}

1. Цой О.Б. Некоторые результаты исследования структуры летних осадков над Средним Поволжьем // Метеорология и гидрология. 1998. Вып.3. С 13-28.

2. Волков С.A. Микроклиматы северной части Волгоградского водохранилища. Дис. ... канд. геол. наук. Саратов, 1974. $148 \mathrm{c}$.

\title{
К ВОПРОСУ О ДЕЛЕНИИ АТМОСФЕРНЫХ ОСАДКОВ НА «ОБЛОЖНЫЕ» И «ЛИВНЕВЫЕ»
}

\section{О.Б. Цой, А.С. Столетова \\ Саратовский государственный университет, кафедра метеорологии и климатологии E-mail:TsoyOB@list.ru}

В статье приводятся результаты опыта разделения «обложной» и «ливневой» составляющих жидких осадков по критерию их интенсивности. Использован новый физический подход, основанный на различии основных осадкообразующих восходящих движений, обусловливающих образование ливневых и обложных осадков. Проанализированы данные плювиографических наблюдений за десять летних периодов (с 1984 по 1993 г.) на одном посту в Пензенской области. Использована нестандартная методика обработки и анализа данных. В результате интенсивности до 0,03 мм/мин могут считаться характеризующими обложные осадки, интенсивности $\geq 0,06$ мм/мин - ливневые. Существует переходный (от обложных к ливневым) диапазон значений интенсивности осадков - 0,03-0,05 мм/мин.

On Question of Division of Atmospheric Precipitations for «Steady Widespread» and "Excess Heavy»

\section{O.B. Tsoi, A.S. Stoletova}

Results of experience in division of "steady widespread» and "excess heavy» parts of liquid precipitation by criterion of their intensity are considered in this paper. New physical approach is based on distinction of main precipitated ascending movements, causing formation of heavy or steady widespread precipitation. The data on pluviographical observations for ten summer periods (1984 1993) at one post in Penza region are analyzed. The non-standard technique of processing and analysis of the data is used. In result, intensity less then $0,03 \mathrm{~mm} / \mathrm{min}$ - can be described as steady widespread precipitation, intensity $\geq 0,06 \mathrm{~mm} / \mathrm{min}$ - heavy precipitation. There is transition range between these intensities of precipitation in the interval of $0,03-0,05 \mathrm{~mm} / \mathrm{min}$.

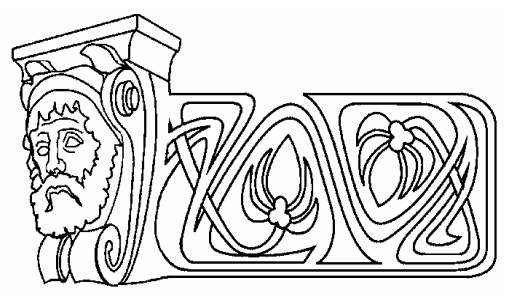

Среди различных классификаций атмосферных осадков одной из наиболее применяемых в научных исследованиях и гидрометеорологической практике, да и в быту, является классификация по характеру их выпадения: моросящие, обложные и ливневые. При этом, однако, четкие общепринятые критерии такой классификации до сих пор не выработаны. Наиболее актуальной эта проблема является для жидких осадков теплого периода, выпадающих с интенсивностями, меняющимися в большем диапазоне значений относительно зимних осадков в средних широтах. Проблема классификации жидких осадков теплого периода применительно к Поволжью обсуждается в данной статье.

Моросящими осадками называют обычно жидкие мелкокапельные (диаметром менее 0,5 мм), медленно оседающие, со скоростью порядка $0,1 \mathrm{~m} / \mathrm{c}$, осадки самых слабых интенсивностей. Интенсивность моросящих осадков разными авторами оценивается практически одинаково - до $0,01-0,015 \mathrm{Mm} / \mathrm{Mин}$ [1-4]. По происхождению моросящие осадки 
чаще всего являются трансформационными, то есть обусловленными трансформационным охлаждением нижнетропосферного слоя одной воздушной массы [4].

Обложные осадки характеризуются относительно длительным выпадением на значительных площадях со слабо меняющейся интенсивностью [3, 5]. Обусловлены крупномасштабными упорядоченными восходящими движениями, то есть являются фронтальными осадками $[4,6]$. Интенсивность обложных осадков оценивается разными авторами $[1,4,6,7]$ в диапазоне от 0,01 до 0,1 мм/мин. При этом наименее определенным является верхний предел диапазона интенсивностей обложных осадков, он варьирует от 0,03 до 0,1 мм/мин. Для его уточнения используются дополнительные критерии, например, градиент высоты слоя осадков между смежными по времени дождями [7] или отношение длительности флуктуации интенсивности к длительности всего дождя [1].

Ливневыми называют обычно интенсивные, относительно локализованные в пространстве осадки с резкими изменениями интенсивности как во времени, так и в пространстве [3, 5]. Такие осадки обусловлены конвективными восходящими потоками, поэтому могут быть как фронтальными, так и внутримассовыми. Проблема уточнения нижней границы диапазона ливневых интенсивностей отмечена выше. Чаще всего ливневыми осадками считают осадки интенсивностью более 0,05 мм/мин [3, 6].

Поскольку в атмосфере часто происходит образование осадков при одновременном действии упорядоченных и конвективных вертикальных движений, то обложные осадки могут накладываться на ливневые, вследствие чего интенсивности первых становятся неявными. Некоторые авторы [1] справедливо называют такие осадки смешанными, хотя этот термин применяется и для определения осадков, смешанных по фазовому составу (жидких и твердых).

Таким образом, из краткого вышеприведенного обзора выделяемые здесь виды осадков являются, по сути, комплексными категориями, определяемыми разными пространственными и временными признаками. При этом пространственные признаки (площадь распространения) определяются лишь качественно, временные (длительность выпадения дождя или флуктуации интенсивности) иногда подвергаются количественной оценке, но также пока точно не определены. Наиболее часто используемым критерием деления осадков в этой классификации является интенсивность их выпадения. Однако если граница между моросящими и обложными осадками по их интенсивности определена в достаточно узком диапазоне значений (0,01-0,015 мм/мин), то разделение обложных и ливневых осадков по величине интенсивности вряд ли можно считать достаточно согласованным у разных авторов. Между тем термины «ливневые» и «обложные» часто используются при характеристике осадков, и неопределенность критериев их разделения вносит некоторую путаницу при сопоставлении результатов различных исследований.

Авторами данной статьи предпринята попытка уточнения диапазонов значений интенсивности, характеризующих «обложную» и «ливневую» составляющие жидких осадков в Поволжье.

Предполагая принципиальное генетическое различие между «обложной» и «ливневой» составляющими осадков, заключающееся в различии их осадкообразующих восходящих движений в атмосфере (крупномасштабный упорядоченный или конвективный подъем воздуха), был предложен новый физический подход к разделению этих составляющих осадков. Ливневые осадки, в значительной степени усиливающиеся термической конвекцией, должны увеличивать значения некоторых своих характеристик (например, сумм и интенсивностей) днем. И наоборот, ночью доля ливневых осадков (в общей сумме осадков за ночь) должна уменьшаться, а доля обложных осадков соответственно увеличиваться. Выявление такой реакции осадков разной интенсивности на смену «день-ночь» и являлось целью проведенного здесь исследования.

Для расчетов использовались данные плювиографических наблюдений экспедиции Центральной аэрологической обсерватории на плювиопосту Б. Елань в Пензенской области за летние периоды (июнь - август) с 1984 по 1993 г. Объем обработанного материала представляет собой 36202 мин записей выпадения осадков. Из них 17518 мин - но- 
чью и 18684 мин - днем. При этом даже с учетом отбракованных записей анализируемый материал составил не менее $90 \%$ от максимально возможного (от всех выпавших дождей) за период.

В работе использовалась специальная, отличная от стандартной, методика обработки плювиоданных. Стандартная методика (применяемая на сети) предполагает осреднение записей дождей на плювиограммах по 10-минутным интервалам. Однако при анализе тонкой структуры дождя (например, дождя продолжительностью несколько минут из отдельного кучево-дождевого облака) интервал в 5-10 мин сопоставим с длительностью всего процесса. Осреднение по 10-минутным интервалам не позволяет выявить все флуктуации интенсивности и продолжительности, а также сглаживает экстремальные флуктуации. Поэтому в настоящей работе использовалась обработка плювиограмм по особым точкам - точкам перегиба кривой записи на плювиоленте, являющимся границами флуктуаций.

Для анализа влияния термической конвекции на характеристики осадков все флуктуации интенсивности осадков были разделены на «дневные», выпадающие с 10 ч до 22 ч местного времени (совпадающего с московским декретным), и «ночные» - с 22 ч до 10 ч. Такое выделение полусуточных периодов, как показано отдельными исследованиями [8], наилучшим образом отражает влияние дневного прогрева (термической конвекции) на процесс осадкообразования летом.
Bce «ночные» и «дневные» флуктуации осадков были распределены по градациям интенсивности с шагом в 0,01 мм/мин. Для каждой градации интенсивности были суммированы соответствующие продолжительности (в минутах) флуктуаций осадков и рассчитаны вклады (в \%) градаций интенсивности в полусуточные (день, ночь) продолжительности. Результаты расчетов приведены в таблице, а также в виде графиков на рисунке. Большие интенсивности ( $\geq 0,1$ мм/мин) для удобства представления объединены в одну градацию. По оси абсцисс указаны начальные значения градаций интенсивности, то есть, например, к точке 0,01 относятся вклады в продолжительность осадков расчетных интенсивностей от 0,01 до 0, 019 мм/мин.

По значениям вкладов видно (таблица, рисунок), что наблюдается вполне определенная тенденция увеличения доли осадков слабых интенсивностей (до 0,03 мм/мин включительно) ночью относительно дневных полусуток. Интенсивные осадки (от 0,06 мм/мин и более), наоборот, ночью заметно уменьшают свои вклады, днем же доля интенсивных осадков однозначно возрастает. Наиболее заметны эти тенденции в крайних градациях интенсивности. Увеличение доли осадков самой слабой интенсивности ночью достигает 9,3\% (рисунок, $a$ ). Увеличение доли самых интенсивных осадков (более 0,1 мм/мин, то есть однозначно ливневых) днем оценивается почти в 7-8\%. Отмеченные закономерности характерны как для всего летнего периода (таблица, рисунок, $a$ ), так и для уменьшенной выборки дождей (июнь-июль)

Вклады осадков различной интенсивности в полусуточные продолжительности в летние сезоны 1984-1993 гг. Пензенская область

\begin{tabular}{|c|c|c|c|c|c|c|c|c|c|c|c|c|c|}
\hline \multirow{2}{*}{\multicolumn{2}{|c|}{ Вклады }} & \multicolumn{12}{|c|}{ Интенсивность, мм/мин } \\
\hline & & $<0,01$ & 0,01 & 0,02 & 0,03 & 0,04 & 0,05 & 0,06 & 0,07 & 0,08 & 0,09 & $>0,099$ & Сумма \\
\hline & & \multicolumn{12}{|c|}{ июнь-август } \\
\hline \multirow{2}{*}{ Ночь } & мин & 6663 & 3859 & 2257 & 1341 & 806 & 587 & 398 & 387 & 172 & 121 & 927 & 17518 \\
\hline & $\%$ & 38 & 22 & 12,9 & 7,7 & 4,6 & 3,4 & 2,3 & 2,2 & 1 & 0,7 & 5,3 & 100 \\
\hline \multirow{2}{*}{ День } & мин & 5359 & 3854 & 2151 & 1416 & 1365 & 604 & 615 & 512 & 310 & 213 & 2285 & 18684 \\
\hline & $\%$ & 28,7 & 20,6 & 11,5 & 7,6 & 7,3 & 3,2 & 3,3 & 2,7 & 1,7 & 1,1 & 12,2 & 100 \\
\hline & & \multicolumn{12}{|c|}{ июнь-июль } \\
\hline \multirow{2}{*}{ Ночь } & мин & 3868 & 2609 & 1419 & 912 & 523 & 452 & 256 & 276 & 131 & 104 & 666 & 11216 \\
\hline & $\%$ & 34,5 & 23,3 & 12,7 & 8,1 & 4,7 & 4 & 2,3 & 2,5 & 1,2 & 0,9 & 5,9 & 100 \\
\hline \multirow{2}{*}{ День } & мин & 3515 & 2484 & 1381 & 1052 & 942 & 302 & 500 & 344 & 192 & 194 & 1736 & 12642 \\
\hline & $\%$ & 27,8 & 19,6 & 10,9 & 8,3 & 7,5 & 2,4 & 4 & 2,7 & 1,5 & 1,5 & 13,7 & 100 \\
\hline
\end{tabular}


Вклад, \%

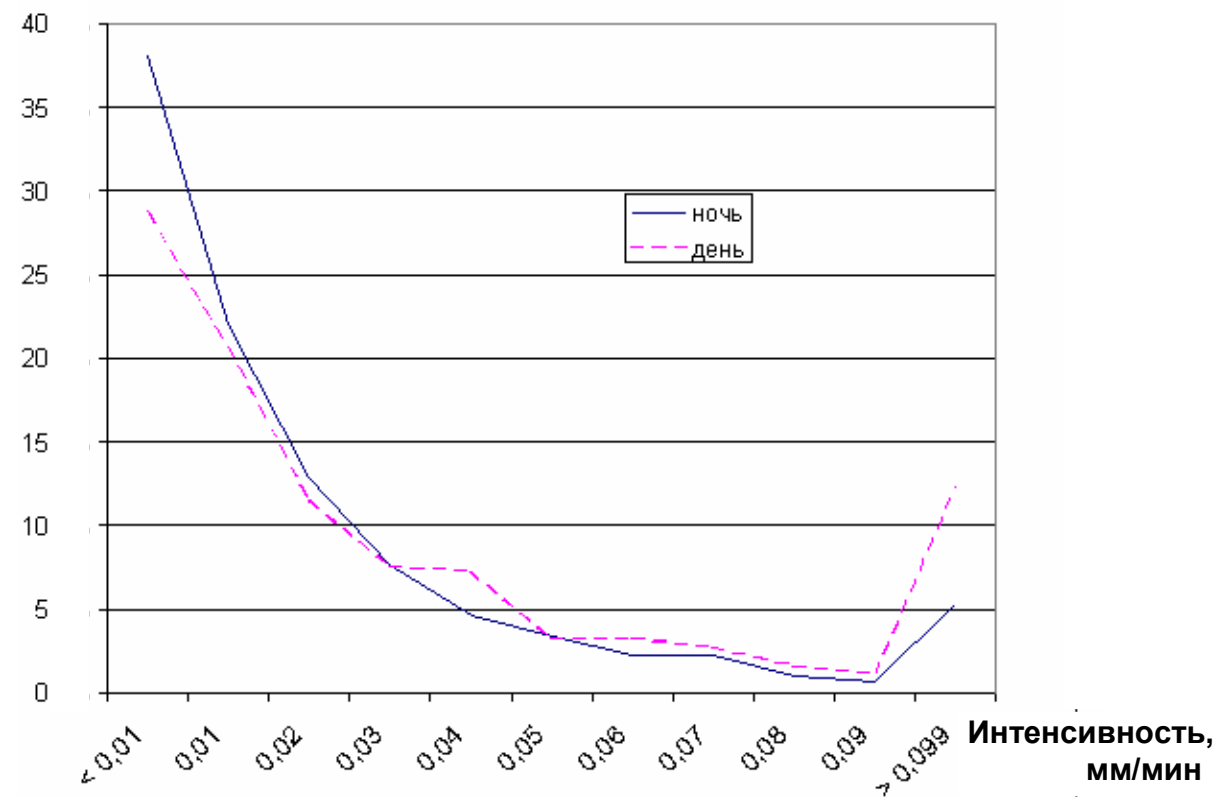

$a$

Вклад, \%

40

35

30

25

20

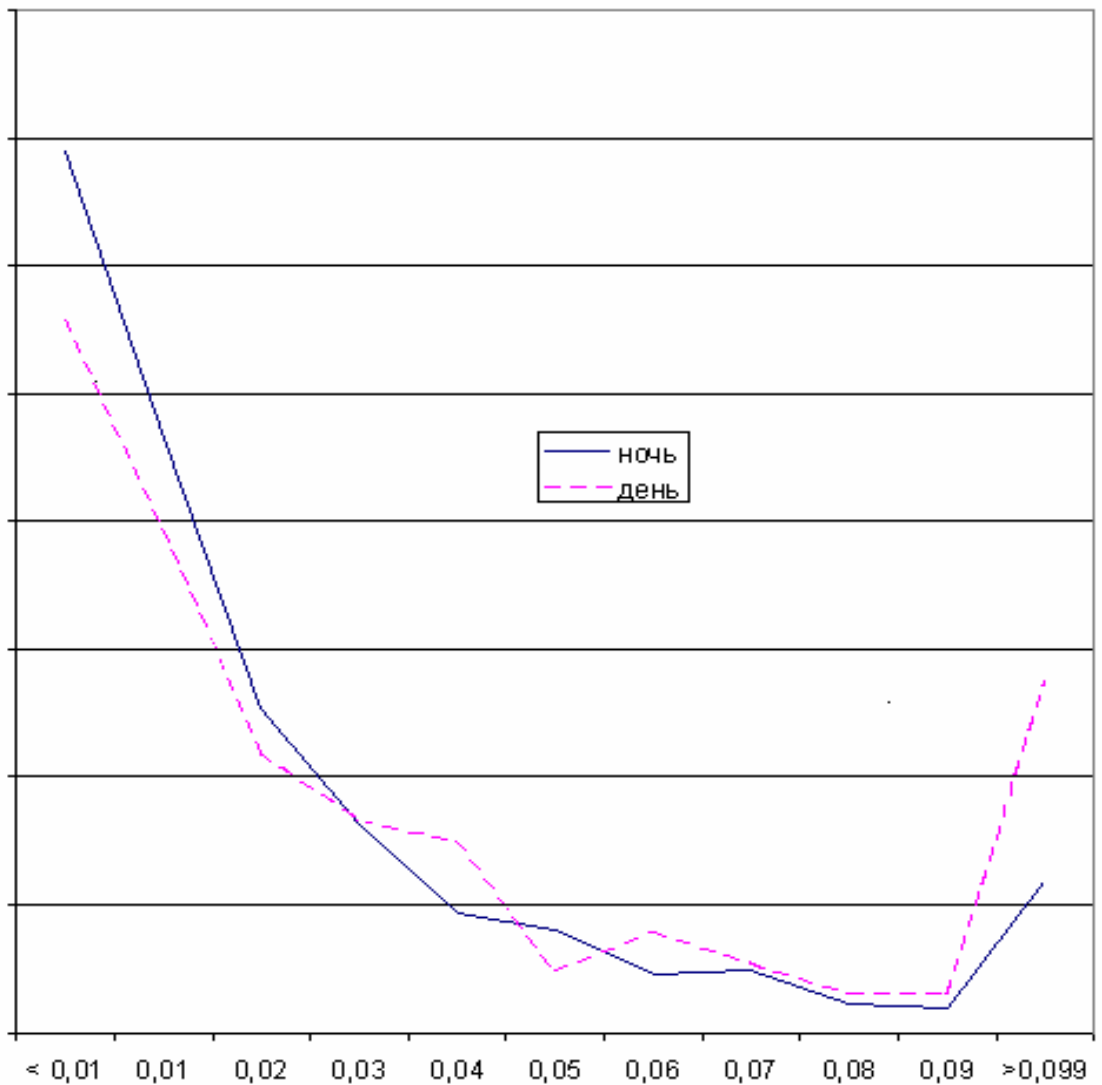

0

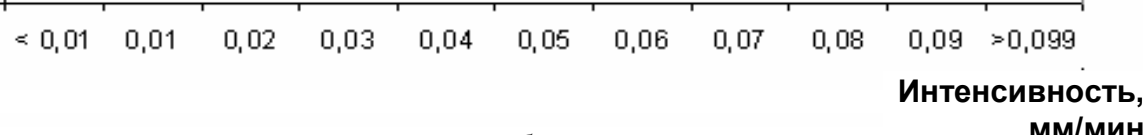

$\sigma$

Мм/МИн

Вклады осадков различной интенсивности в полусуточные продолжительности в летние сезоны 1984-1993 гг. Пензенская область: $a$-в июне-августе; $\sigma$ - в июне-июле 
(таблица, рисунок, б). Дальнейшее уменьшение выборки для проведения помесячного анализа в указанный десятилетний период нецелесообразно, так как из-за усиления влияния циркуляционных факторов на внутрисуточное распределение осадков (при сокращении объема данных) фактор термической конвекции становится менее явным. Наоборот, увеличение объема анализируемого материала приводит к уравниванию влияния макроциркуляционного фактора (повторяемости циклонов и атмосферных фронтов) на выпадение осадков в течение суток

По полученным результатам видно, что отсутствует четкое граничное значение, разделяющее ливневые и обложные интенсивности осадков. В градациях интенсивностей от 0,03 до 0,05 мм/мин наблюдаются любые соотношения между ночными и дневными вкладами, не соответствующие отмеченным выше тенденциям. Значит, существует некоторый переходный диапазон интенсивностей между значениями, которые можно определенно отнести к интенсивностям обложных и ливневых осадков по их принципиально различной реакции на смену дня и ночи, то есть на фактор термической конвекции. В некоторых других исследованиях $[6,8]$ принимались переходные диапазоны интенсивностей без соответствующего физического обоснования, но они практически совпадали по значениям с выявленными в данной работе. Условно, в качестве граничного критерия интенсивности между ливневыми и обложными осадками можно принимать середину данного диапазона, то есть значение - 0,04 мм/мин.
Таким образом, в результате применения нового физического подхода, в данной работе осуществлена попытка уточнения критерия разделения «обложной» и «ливневой» составляющих жидких осадков по их интенсивностям для одного из регионов Поволжья. Интенсивности величиной до 0,03 мм/мин могут считаться характеризующими обложные осадки, величиной от 0,06 мм/мин и более - ливневые осадки. Существует переходный (от обложных к ливневым) диапазон значений интенсивности $-0,03-0,05$ мм/мин, совпадающий с аналогичными, используемыми в других исследованиях.

Представляется целесообразным провести подобный анализ по другим регионам и по большим временным периодам.

\section{Библиографический список}

1. Акулиничева A.A. Методика определения упорядоченных и конвективных скоростей по плювиографическим данным // Тр. ГМЦ СССР. 1969. Вып.57. С.74-102.

2. Богатырь Л.Ф. К характеристике дождей на экспериментальном метеорологическом полигоне // Тр. УкрНИГМИ. 1967. Вып.67. С.45-50.

3. Литвинов И.В. Осадки в атмосфере и на поверхности земли. Л., 1980. 208 с.

4. Орлова E.M. Краткосрочный прогноз атмосферных осадков. Л., 1979. 168 с

5. Хромов С.П., Мамонтова Л.И. Метеорологический словарь. Л., 1974. 454 с.

6. Алибегова Ж.Д. Пространственно-временная структура полей жидких осадков. Л., 1979. 229 с.

7. Курейко И.А. О разделении обложных и ливневых осадков // Тр. УкрНИГМИ. 1978. Вып.67. С.23-27.

8. Цой О.Б. Некоторые результаты исследования структуры летних осадков над Средним Поволжьем // Метеорология и гидрология. 1998. Вып.3. С.13-28. 